\title{
Breviscapine ameliorates hypertrophy of cardiomyocytes induced by high glucose in diabetic rats via the PKC signaling pathway
}

\author{
Min WANG, Wen-bin ZHANG, Jun-hui ZHU, Guo-sheng FU, Bin-quan ZHOU* \\ Key Laboratory of Biotherapy of Zhejiang Province, Sir Run Run Shaw Hospital, College of Medicine, Zhejiang University, Hangzhou \\ 310016, China
}

\begin{abstract}
Aim: To investigate the influence of breviscapine on high glucose-induced hypertrophy of cardiomyocytes and the relevant mechanism in vitro and in vivo.

Methods: Cultured neonatal cardiomyocytes were divided into i) control; ii) high glucose concentrations; iii) high glucose+PKC inhibitor Ro-31-8220; iv) high glucose+breviscapine; or v) high glucose+NF-kB inhibitor BAY11-7082. Cellular contraction frequency and volumes were measured; the expression of protein kinase $\mathrm{C}$ (PKC), NF-kB, TNF- $\alpha$, and c-fos were assessed by Western blot or reverse transcription-polymerase chain reaction (RT-PCR). Diabetic rats were induced by a single intraperitoneal injection of streptozotocin, and randomly divided into i) control rats; ii) diabetic rats; or iii) diabetic rats administered with breviscapine (10 or $\left.25 \mathrm{mg}^{\mathrm{kg}} \mathrm{g}^{-1} \cdot \mathrm{d}^{-1}\right)$. After treatment with breviscapine for six weeks, the echocardiographic parameters were measured. All rats were then sacrificed and heart tissue was obtained for microscopy. The expression patterns of PKC, NF-kB, TNF- $\alpha$, and c-fos were measured by Western blot or RTPCR.

Results: Cardiomyocytes cultured in a high concentration of glucose showed an increased pulsatile frequency and cellular volume, as well as a higher expression of PKC, NF-KB, TNF- $\alpha$, and c-fos compared with the control group. Breviscapine could partly prevent these changes. Diabetic rats showed relative cardiac hypertrophy and a higher expression of PKC, NF-KB, TNF- $\alpha$, and c-fos; treatment with breviscapine could ameliorate these changes in diabetic cardiomyopathy.

Conclusion: Breviscapine prevented cardiac hypertrophy in diabetic rats by inhibiting the expression of PKC, which may have a protective effect in the pathogenesis of diabetic cardiomyopathy via the PKC/NF-KB/c-fos signal transduction pathway.
\end{abstract}

Keywords: diabetic cardiomyopathy; protein kinase C; cardiomegaly; breviscapine

Acta Pharmacologica Sinica (2009) 30: 1081-1091; doi: 10.1038/aps.2009.95; published online 13 July 2009

\section{Introduction}

The worldwide prevalence of diabetes mellitus was estimated to be $2.8 \%$ in 2000 and is projected to reach $4.4 \%$ by $2030^{[1]}$. Diabetic cardiomyopathy that occurs independently of coronary artery disease and hypertension is one of the most prevalent cardiovascular complications of diabetes ${ }^{[2,3]}$. Many epidemiological and clinical studies have shown that chronic hyperglycemia is a major initiator of diabetic cardiovascular complications. High glucose regulates structural and functional changes of cardiomyocytes via the activation of several signal transduction pathways, such as increased polyol pathway flux, altered cellular redox states, increased formation of diacylglycerol (DAG) and the subsequent activation of pro-

* To whom correspondence should be addressed.

E-mail wangmin_hzzjusyf@yeah.net

Received 2009-03-20 Accepted 2009-05-07 tein kinase C (PKC) isoforms, and accelerated non-enzymatic formation of advanced glycated end products ${ }^{[4,5]}$. Increased expression and activity of PKC causes modifications in the extracellular matrix, induces hypertrophy of cardiomyocytes, microangiopathy of the heart, fibrosis of the interstitium, and eventually leads to heart failure ${ }^{[6]}$. Among the signal pathways listed above, the DAG-PKC signal pathway is considered to be one of the most important intracellular transduction pathways that functions as a core effector in the onset and progression of diabetic cardiomyopathy ${ }^{[7]}$.

The PKC family comprises more than ten different isozymes; with respect to the heart, PKC- $\alpha$ and PKC- $\beta 2$ are the predominant $\mathrm{Ca}^{2+}$-dependent PKC isoforms. A number of reports have associated PKC with many structural and functional abnormalities in cardiovascular disease such as cardiac hypertrophy, dilated cardiomyopathy, ischemic injury and heart failure. Additionally, inhibition of PKC has been reported to 
have a protective effect on both structural abnormalities and cardiac dysfunction. Most studies have shown that hyperglycemia could induce over-expression of PKC- $\alpha$ and PKC- $\beta 2$ in the early stages of the pathological development of diabetic cardiomyopathy, and is likely to be responsible for the pathologies in diabetic cardiomyopathy ${ }^{[8,9]}$. However, the exact role that PKC plays in the alteration of cardiomyocytes and its underlying downstream signal transduction pathways is still unclear.

NF-кB is a transcription factor that directly regulates the expression of a number of genes that are involved in the stress and inflammatory response following a variety of physiological or pathological stimuli ${ }^{[10]}$. Recent studies have shown that activation of NF- $\mathrm{kB}$ may function as a causal event in the cardiac hypertrophic response as modeled in cultured cardiomyocytes ${ }^{[11]}$ and that NF-kB inhibition could attenuate or block the hypertrophy of cultured cardiomyocytes ${ }^{[12]}$. As NF-kBinduced oxidative stress generated by hyperglycemia is one of the major mediators of diabetic cardiomyopathy ${ }^{[13]}, \mathrm{NF}-\mathrm{kB}$ is considered as a necessary regulator of the cardiac response in the pathogenesis of diabetic cardiomyopathy ${ }^{[14]}$.

Tumor necrosis factor alpha (TNF-a) is a significant contributor to myocardial dysfunction as cardiomyocytes have been identified as a principal target of the proinflammatory actions of TNF-a. Significantly increased expression of TNF-a is found in stretch-induced or hemodynamic overload-induced cardiac hypertrophy in cultured cardiomyocytes. In models of heart failure and cardiomyopathy, TNF- $\alpha$ transcription can

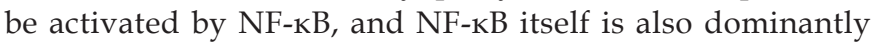
regulated by TNF- $\alpha$. Increased expression of TNF- $\alpha$ triggers NF- $\mathrm{kB}$ translocation to the nucleus, where it activates transcription of many inflammatory and immune response target genes.

c-fos is one of the immediate early genes and fetal contractile protein genes that regulates protein synthesis in cardiomyocytes. It is reported to be stimulated in ischemic injury, heart failure and cardiomyopathy ${ }^{[15]}$. Increased expression of c-fos has also been reported in both angiotensin II-induced or mechanical stress-induced hypertrophy of cardiomyocytes. The PKC/c-fos pathway has been shown to be involved in endothelin-1-induced proliferation and hypertrophy of rat cardiac myocytes $^{[16]}$. As most of the studies above were carried out in models of heart failure and ischemic injury, little is known about the effect of c-fos on cardiac hypertrophy with respect to diabetic cardiomyopathy.

Breviscapine $\left(\mathrm{C}_{21} \mathrm{H}_{18} \mathrm{O}_{12}\right)$ is a flavonoid extracted from Erigeron breviscapus and its essential active ingredient is flavones. Based on experimental study and clinical observation, the pharmacological actions of breviscapine include dilating micro-blood vessels, reducing blood viscosity, and improving microcirculation. Studies have shown that breviscapine could inhibit the activity of PKC ${ }^{[17-19]}$ and has a protective effect on diabetic nephropathy, but little is known about the influence of breviscapine on diabetic cardiomyopathy and its underlying mechanisms.

In this study, we aimed to investigate the role of PKC and its downstream PKC/NF-kB/c-fos signaling pathway in the hypertrophy associated with diabetic cardiomyopathy, and also to study the protective effect of the PKC inhibitor, breviscapine, in the pathogenesis of diabetic cardiomyopathy.

\section{Materials and methods \\ Experimental animals}

One-day-old Sprague-Dawley rats (provided by the experimental animal center of Zhejiang University) were used for in vitro cell cultures; male Sprague-Dawley rats [certificate number: SCXK (Zhe) 2007-0029; body weight: 166.72 \pm 10.26 g, total range 138-186 g] were used for the animal experiments. All procedures were approved by the Ethics Committee for the Use of Experimental Animals in Zhejiang University; all the experiments followed the instructions for animal care and usage provided by the institution.

\section{Drugs and chemicals}

Trypsin and DMEM were purchased from Gibco Chemical Co; glucose, streptozotocin, Ro-31-8220 and BAY11-7082 were obtained from Sigma Chemical Co. Breviscapine was obtained from Shanghai RongHe Bioengineering Co $\left(\mathrm{C}_{21} \mathrm{H}_{18} \mathrm{O}_{12}\right.$, purity $>98 \%$; Shanghai, China). Primary antibodies included mouse anti-PKC- $\alpha$, rabbit anti-PKC- $\beta 2$, goat anti-p-PKC- $\alpha$, goat antip-PKC- $\beta 2$, mouse anti-NF- $\mathrm{B}$, rabbit anti-p-NF- $\mathrm{kB}$, rabbit antic-fos antibody and rabbit anti- $\beta$-actin (Santa Cruz). Secondary antibodies included goat anti-rabbit, rabbit anti-goat, and goat anti-mouse antibody (Zhongshan Co, Beijing, China). The TNF-a primers were (387 bp): 5'-GAA CAA CCC TAC GAG CAC CT-3', 5'-GGG TAG TTT GGC TGG GAT AA-3'; the GAPDH primer (350 bp): 5'-GGT CGG AGT CAA CGG ATT TG-3', 5'-ATG AGC CCC AGC CTT CTC CAT-3' (Shanghai Sangon Biological Engineering Technology and Services Co, Shanghai, China). dNTPs, Taq enzyme, M-MLV, $\mathrm{MgCl}_{2}$ and RNasin were purchased from Promega Co; Oligo(dT $)_{15}$ was obtained from Shanghai Sangon Biological Engineering Technology and Services Co.

\section{Culture of neonatal rat ventricular myocytes}

Ventricular myocytes were cultured as described previously $^{[20,21]}$. Briefly, one-day-old Sprague-Dawley rats were sacrificed and their hearts were isolated, and the ventricles were dissected and digested with a buffer solution containing $0.125 \%$ trypsin and $1 \%$ collagenase for $10 \mathrm{~min}$ at $37{ }^{\circ} \mathrm{C}$. The cell supernatant was collected and DMEM cell culture medium containing $15 \%$ fetal bovine serum was added to stop the digestive effect of trypsin and collagenase. The above steps were repeated three to five times until the ventricles were completely digested; the cell supernatant was then collected by centrifugation, after which the pellet was resuspended and collected by centrifugation again. After resuspension with DMEM and the cell culture medium containing $15 \%$ fetal bovine serum and penicillin-streptomycin, the cell suspension was diluted to $(1-5) \times 10^{5} / \mathrm{mL}$ and placed in 6-well cell culture plates in a humidified $5 \% \mathrm{CO}_{2} / 95 \%$ at $37{ }^{\circ} \mathrm{C}$. In the first three days, $5-\mathrm{BrU}(0.1 \mathrm{mmol} / \mathrm{L})$ was added to inhibit the growth of 
fibroblasts. The cells were changed to a serum-free DMEM culture medium and cultured for $48 \mathrm{~h}$ before being divided into different groups.

\section{Division of cultured cardiomyocytes}

After the initial $48 \mathrm{~h}$ serum-free culture, cells were divided into different glucose levels according to previously described research $^{[22]}$ as follows: the control glucose $(5 \mathrm{mmol} / \mathrm{L})$ group, high glucose (25.5 mmol/L) group, high glucose plus PKC inhibitor Ro-31-8220 (50 nmol/L) group, high glucose plus breviscapine $(10,20$, and $60 \mathrm{mmol} / \mathrm{L})$ group, and high glucose plus NF-kB inhibitor BAY11-7082 (5 $\mu \mathrm{mol} / \mathrm{L})$ group. After the addition of those drugs, the different groups of cardiomyocytes were cultured for an additional $12 \mathrm{~h}$.

\section{Determination of cellular pulsatile frequency and measurement of cellular size}

An inverted microscope and dish were put into lucite couveuse, which was equipped with a homoiothermy air convection assembly. The dishes were fully covered by convection air at $37^{\circ} \mathrm{C}$. For the study of cellular pulsatile frequencies, five fields were randomly chosen from each group, and 20 individual cells were counted from each field using the high power $(\times 400)$ ocular lens of the inverted microscope. The volume of ventricular myocytes was obtained by measuring cellular diameter under an inverted microscope; five fields were randomly chosen from each group and 20 individual cells were counted from each field for cellular size measurements.

\section{Western blot analysis of cultured cardiomyocytes}

The cells were washed twice with PBS and lysed at $4{ }^{\circ} \mathrm{C}$ with lysis buffer containing $25 \mathrm{mmol} / \mathrm{L}$ Tris (pH 7.4), $5 \mathrm{mmol} / \mathrm{L}$ EDTA, $10 \mathrm{mmol} / \mathrm{L}$ sodium pyrophosphate, $1 \mathrm{mmol} / \mathrm{L} \mathrm{Na}_{3} \mathrm{VO}_{4}$, $1 \mathrm{mmol} / \mathrm{L}$ dithiothreitol, $1 \mathrm{mmol} / \mathrm{L}$ PMSF and $10 \mathrm{mg} / \mathrm{L}$ aprotinin. The protein expression of $\mathrm{PKC}, \mathrm{NF}-\mathrm{kB}$, and $\mathrm{c}$-fos were measured by Western blot and normalized to the protein level of $\beta$-actin. Equal amounts of total protein $(40 \mu \mathrm{g})$ from each lysate were resolved by SDS/PAGE $[10 \%(w / v)$ gel] and then transferred into PVDF membranes. After the membranes were blocked with $5 \%$ non-fat milk dissolved in TBS $(20 \mathrm{mmol} / \mathrm{L}$ Tris $\mathrm{HCl}$ and $0.5 \mathrm{~mol} / \mathrm{L} \mathrm{NaCl}, \mathrm{pH} 7.4$ ) for $1 \mathrm{~h}$ at room temperature, the filters were incubated respectively with primary antibodies (mouse anti-PKC- $\alpha$, rabbit anti-PKC- $\beta 2$, goat antip-PKC- $\alpha$, goat anti-p-PKC- $\beta 2$, mouse anti-NF-kB, rabbit antip-NF- $\mathrm{B}$ and rabbit anti-c-fos antibody, Santa Cruz, 1:1000 dilution) overnight at $4{ }^{\circ} \mathrm{C}$. After being washed three times with TBST buffer (0.05\% Tween 20 in TBS, pH 7.4) for $10 \mathrm{~min}$ each time, the filters were incubated with horseradish peroxidase-conjugated secondary antibodies for $1 \mathrm{~h}$, followed by three washes with TBST buffer for 10 min each. At last, antibody-antigen complexes were detected in all the membranes by enhanced chemiluminescence (ECL)-detection reagents and exposed to an X-OMAT AR X-ray film (Kodak Inc). The intensity of these protein bands was quantified by densitometry and normalized to $\beta$-actin (Zhongshan Bio-tech, China).
Reverse transcription-polymerase chain reaction (RT-PCR) analysis of cultured cardiomyocytes

The cultured cardiomyocytes were washed twice with PBS and lysed in $1 \mathrm{ml}$ of trizol reagent for $5 \mathrm{~min}$. Total RNA was extracted with Trizol reagent according to the manufacturer's instructions. RNA content was assessed by light absorbance at $260 \mathrm{~nm}$, and purity was determined according to $A_{260} / A_{280}$ ratios. A quantity of $5 \mu \mathrm{g}$ of total RNA was reversely transcribed into cDNA in a $50-\mu \mathrm{L}$ reaction mixture containing $0.1 \mu \mathrm{g}$ random hexamers and $400 \mathrm{U}$ of M-MLV transcriptase, and subsequently amplified by PCR using primers listed above. The $25 \mu \mathrm{L}$ of reaction mixture for PCR contained 2 $\mu \mathrm{L}$ of the cDNA, $20 \mu \mathrm{mol} / \mathrm{L}$ of each $\mathrm{dNTP}, 400 \mathrm{pmol}$ of each specific primer, $25 \mathrm{mmol} / \mathrm{L} \mathrm{MgCl}_{2} 1.5 \mu \mathrm{L}$, and $1 \mathrm{U}$ Taq DNA polymerase. The resulting products were separated on $1.2 \%$ agarose gel and stained with ethidium bromide. The intensity of the bands was quantified by an image analysis scanning system, and normalized by GAPDH as a control.

\section{Animal experiment groups and measurement of cardiac hypertrophy}

Diabetes in rats was induced by an intraperitoneal injection of $70 \mathrm{mg} / \mathrm{kg}$ streptozotozin, and the age and weight-matched control rats received saline only. All the rats were housed in groups of four per cage and given free access to food and water at a constant temperature of $22 \pm 2{ }^{\circ} \mathrm{C}$, with a $12 \mathrm{~h}$ light/ dark cycle. About $72 \mathrm{~h}$ after streptozotocin injection, blood samples were taken from the caudal vein to measure glucose levels using a glucometer (One Touch II glucometer) and were repeated every week for each rat. Rats in which glucose levels measured $>16.7 \mathrm{mmol} / \mathrm{L}$ at least three times were categorized as diabetic rats. Four weeks after injection of strepozotozin or vehicle, all rats were randomly divided into the following groups: i) normal control rats (Control, $n=10$ ); ii) untreated diabetic rats (DM, $n=10)$; iii) diabetic rats administered with low dose breviscapine $\left(10 \mathrm{mg} \cdot \mathrm{kg}^{-1} \cdot \mathrm{d}^{-1}, \mathrm{DM}+\mathrm{LDB}, n=10\right)$; or iv) diabetic rats administered with high-dose breviscapine (25 $\left.\mathrm{mg} \cdot \mathrm{kg}^{-1} \cdot \mathrm{d}^{-1}, \mathrm{DM}+\mathrm{HDB}, n=10\right)$. Breviscapine was administered through an intragastric tube daily for six weeks and the control rats received saline only. In total, two rats in the DM group, and in the DM+LBD and the DM+HBD groups, we both found one rat dead during the experimental period. At the end of the experiment, all rats in different groups were weighed and anesthetized with $10 \%$ hydrated chloral (400 mg/ kg); then, echocardiography was performed using a Hewlett-Packard 5500 instrument (Hewlett-Packard Co) with a 14-MHz compact linear-array probe. Echocardiographic measurements were taken on M-mode in triplicate for each rat. The following measurements were taken to evaluate the cardiac structure and function: interventricular septal dimensions, left ventricular posterior wall dimensions, and left ventricular internal dimensions at end diastole (IVSd, LVPWd, and LVIDd, respectively) and at end systole (IVSs, LVPWs, and LVIDs, respectively). Moreover, these dimensions were also used to calculate the cardiac function parameters such as ejection fraction (EF), IVS percentage and LVPW percentage. 
The rats were then killed by cervical dissociation, the hearts were isolated, and the whole heart weight (LW) and the left ventricular weight (LVW) of each rat were measured, respectively.

\section{Transmission electron microscopy}

Selected samples of cardiac tissue from rats of each group were minced into small pieces $\left(\leq 1 \mathrm{~mm}^{3}\right)$, and fixed in $2.5 \%$ glutaraldehyde in $0.1 \mathrm{~mol} / \mathrm{L}$ sodium cacodylate buffer $(\mathrm{pH} 7.3$ ) for $2 \mathrm{~h}$. The specimens were then rinsed in buffer, post-fixed in cacodylate-buffered $2 \% \mathrm{OsO}_{4}$, stained en bloc in uranyl acetate, dehydrated in an ethanol gradient, and embedded in epoxy resin by standard procedures. Finally, 50-70 mm superthin slices were prepared. Thin sections were stained with uranyl acetate and lead citrate and examined with a Philips TECNA10 electron microscope.

\section{Western blot analysis of animal heart tissues}

After the hearts were removed rapidly from rats, the atria and aorta were cut off, then the ventricles were freeze-clamped at liquid $\mathrm{N}_{2}$ temperature and stored at $-80^{\circ} \mathrm{C}$. Total proteins were extracted from the frozen LV tissues and the concentration was determined by the Lowry method. The myocardial expression of PKC, NF- $\mathrm{KB}$, and c-fos was measured by Western blot and normalized to the protein level of $\beta$-actin as described above.

\section{RT-PCR analysis of animal heart tissues}

Ventricular tissues were pulverized to a powder and lysed in 1 $\mathrm{mL}$ of Trizol reagent for $5 \mathrm{~min}$. Total RNA was extracted with Trizol reagent according to the manufacturer's instructions and assessed by light absorbance at $260 \mathrm{~nm}$; purity was determined according to $A_{260} / A_{280}$ ratios. A quantity of $5 \mu \mathrm{g}$ of total RNA was reversely transcribed and subsequently amplified by PCR as described above. The resulting products were separated on $1.2 \%$ agarose gel and stained with ethidium bromide. The intensity of the bands was quantified by an image analysis scanning system, and normalized by GAPDH as the control.

\section{Statistics}

All data were presented as mean \pm SEM, and were analyzed using SPSS 15.0 software. Comparisons among groups were made by an unpaired Student's $t$ test. A value of $P<0.05$ was considered statistically significant.

\section{Results}

Breviscapine decreased the pulsatile frequency and cellular size of cardiomyocytes cultured in high glucose levels

The cardiomyocytes cultured in a high glucose concentration showed an increased pulsatile frequency and higher cellular volumes compared with those cultured in normal glucose levels $(P<0.05)$. After adding PKC inhibitor Ro-31-8220 (50 $\mathrm{nmol} / \mathrm{L})$, breviscapine $(10,20$, and $60 \mathrm{mmol} / \mathrm{L})$, and NF-KB inhibitor BAY11-7082 (5 $\mathrm{mmol} / \mathrm{L})$, the pulsatile frequency and cellular size of cardiomyocytes decreased significantly $(P<0.05)$. The result is shown in Table 1 .

Table 1. Effect of Ro-31-8220, BAY11-7082, breviscapine on pulsatile frequency and cellular size of cultured cardiomyocytes.

$\begin{array}{cr}\text { Diameter } & \text { Pulsatile } \\ (\mu \mathrm{m}) & \begin{array}{c}\text { frequency } \\ (\mathrm{bpm} / \mathrm{min})\end{array}\end{array}$

Normal glucose $(5 \mathrm{mmol} / \mathrm{L})$

High glucose $(25.5 \mathrm{mmol} / \mathrm{L})$

High glucose+BAY11-7082

High glucose+breviscapine $(10 \mathrm{mmol} / \mathrm{L})$

High glucose+breviscapine $(20 \mathrm{mmol} / \mathrm{L})$

High glucose+breviscapine $(60 \mathrm{mmol} / \mathrm{L})$
High glucose+Ro-31-8220

$\begin{array}{ll}18.64 \pm 0.83 & 63.35 \pm 2.830 \\ 24.29 \pm 1.04^{\mathrm{b}} & 86.04 \pm 4.299^{\mathrm{b}} \\ 19.68 \pm 1.01^{\mathrm{e}} & 78.55 \pm 4.024^{\mathrm{e}} \\ 20.03 \pm 0.88^{\mathrm{e}} & 78.51 \pm 3.669^{\mathrm{e}} \\ 21.49 \pm 1.22^{\mathrm{e}} & 81.33 \pm 4.652^{\mathrm{e}} \\ 20.74 \pm 1.14^{\mathrm{eh}} & 76.57 \pm 3.441^{\mathrm{eh}} \\ 19.71 \pm 0.97^{\mathrm{e}} & 73.00 \pm 3.551^{\mathrm{ek}}\end{array}$

Compared with normal glucose $(5 \mathrm{mmol} / \mathrm{L})$ group, the pulsatile frequency and diameters of cardiomyocytes cultured in high glucose (25.5 mmol/L) increased significantly, after adding Ro-31-8220, BAY117082 , and breviscapine, the pulsatile frequency and size of the cells all decreased significantly, the reverse effect was more obvious as the concentration of breviscapine increased. The results were expressed as means \pm SEM ( $n=100)$. ${ }^{b} P<0.05$ vs control group (glucose: $5 \mathrm{mmol} / \mathrm{L}$ ). ${ }^{e} P<0.05$ vs high glucose group (glucose: $25.5 \mathrm{mmol} / \mathrm{L}$ ), ${ }^{\mathrm{h}} \mathrm{P}<0.05$ vs high glucose+breviscapine $(10 \mathrm{mmol} / \mathrm{L})$ group. ${ }^{\mathrm{k}} P<0.05$ vs high glucose+breviscapine (20 mmol/L) group.

Breviscapine decreased the expression and activity of PKC- $\alpha$ and PKC- $\beta 2$ in cardiomyocytes cultured in high glucose levels

Cardiomyocytes cultured in high glucose levels showed higher expression of PKC- $\alpha$ and PKC- $\beta 2$ and increased activity of PKC- $\alpha$ and PKC- $\beta 2$ at the same time, as reflected by higher expression of $p-P K C-\alpha$ and $p-P K C-\beta 2$ than seen in the control group $(P<0.05)$. After adding PKC inhibitor Ro-318220 and breviscapine $(10 \mathrm{mmol} / \mathrm{L}, 20 \mathrm{mmol} / \mathrm{L}, 60 \mathrm{mmol} / \mathrm{L})$, the expression and activity of PKC- $\alpha$ and PKC- $\beta 2$ decreased significantly $(P<0.05$; Figures 1,2$)$.

Breviscapine decreased the expression of NF-kB, TNF- $\alpha$, and c-fos in cardiomyocytes cultured in high glucose levels

The expression of NF- $\mathrm{kB}$, TNF- $\mathrm{a}$, and c-fos was higher in cardiomyocytes cultured in high glucose levels than in those cultured in normal glucose levels, as the protein level of NF- $\mathrm{kB}$, $\mathrm{p}-\mathrm{NF}-\mathrm{kB}, \mathrm{c}-\mathrm{fos}$, and mRNA level of TNF-a all significantly increased $(P<0.05)$. After adding PKC inhibitor, Ro-31-8220, breviscapine $(10,20$, and $60 \mathrm{mmol} / \mathrm{L})$ and NF- $\mathrm{kB}$ inhibitor BAY11-7082, the expression of NF-kB, TNF- $\alpha$ and c-fos all decreased significantly $(P<0.05)$, as shown in Figures 3,4 , and 5.

\section{Breviscapine ameliorated cardiac hypertrophy and dysfunction in} diabetic rats

The body weight (BW), blood glucose (BG) level, LVW-to-HW (left ventricular weight to heart weight ratio), LVW-to-BW (left ventricular weight to body weight ratio) and HW-to-BW (heart weight to body weight ratio) of all the rats in different groups are presented in Table 2. The STZ-induced diabetic rats had significantly lower mean body weights than those of the age-matched control rats $(P<0.05)$. Breviscapine treat- 

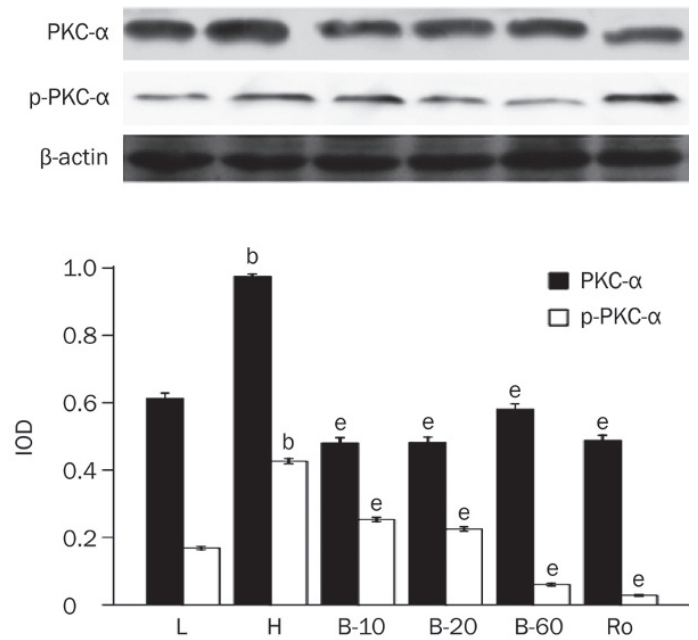

Figure 1. Breviscapine decreased the expression of PKC- $\alpha$ in high glucose cultured cardiomyocytes. Cardiomyocytes cultured in high glucose levels showed higher expression and activity of PKC- $\alpha$ compared with control group. After adding PKC inhibitor Ro-31-8220 (50 nmol/L) and breviscapine $(10,20$, and $60 \mathrm{mmol} / \mathrm{L})$, the expression and activity of PKC- $\alpha$ decreased. $n=4$ or 5 . Mean \pm SEM. ${ }^{b} P<0.05$ vs control group. ${ }^{e} P<0.05$ vs high glucose group. (L: control glucose group; $\mathrm{H}$ : high glucose group; Ro: high glucose+PKC inhibitor Ro-31-8220 group; B-10: high glucose+10 mmol/L breviscapine; B-20: high glucose $+20 \mathrm{mmol} / \mathrm{L}$ breviscapine; B-60: high glucose+60 mmol/L breviscapine group).

ment significantly alleviated the weight loss in diabetic rats $(P<0.05)$. The average blood glucose levels were more than $16.7 \mathrm{mmol} / \mathrm{L}$ in the diabetic group and remained at this level during the experimental period of ten weeks; treatment with low $\left(10 \mathrm{mg} \cdot \mathrm{kg}^{-1} \cdot \mathrm{d}^{-1}\right)$ or high $\left(25 \mathrm{mg} \cdot \mathrm{kg}^{-1} \cdot \mathrm{d}^{-1}\right)$ doses of breviscapine did not affect the blood glucose levels in diabetic rats. The HW and LVW of the diabetic rats were lower than those of the control rats $(P<0.05)$, but the LVW-to-BW and LVWto-HW ratios in diabetic rats were significantly higher than those of the control rats $(P<0.05)$. After treatment with breviscapine, the HW and LVW of diabetic rats increased while the LVW-to-BW and LVW-to-HW ratios decreased significantly compared to diabetic rats $(P<0.05)$. The lower EF, IVS\% and LVPW\% showed that diabetic rats displayed impaired cardiac function $(P<0.05)$. At the same time, diabetic rats showed rela tive cardiac hypertrophy, as presented by the increased ratio
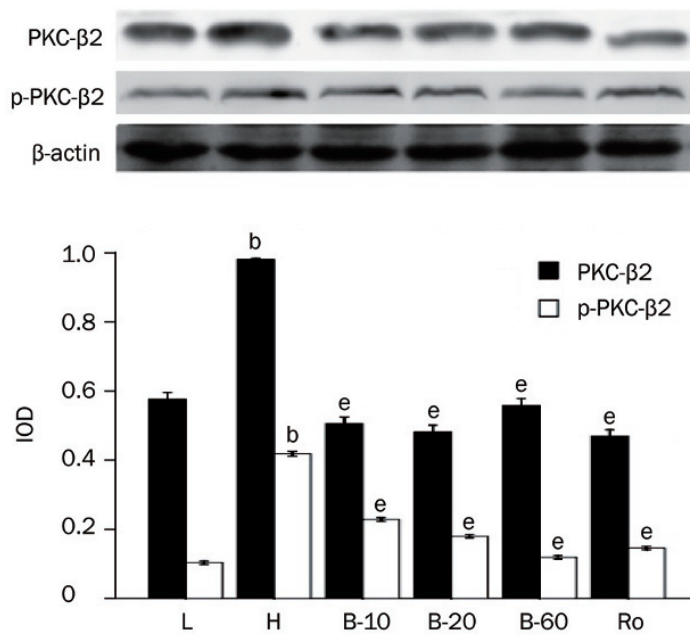

Figure 2. Breviscapine decreased the expression of PKC- $\beta 2$ in high glucose cultured cardiomyocytes. Cardiomyocytes cultured in high glucose levels showed higher expression and activity of PKC- $\beta 2$ compared with control group. After adding PKC inhibitor Ro-31-8220 (50 nmol/L) and breviscapine $(10,20$, and $60 \mathrm{mmol} / \mathrm{L})$, the expression and activity of PKC- $\beta 2$ decreased. The results were shown in Figure 2 expressed as means \pm SEM ( $n=4$ or 5 ). ${ }^{b} P<0.05$ vs control group. ${ }^{e} P<0.05$ vs high glucose group. (L: control glucose group; $\mathrm{H}$ : high glucose group; Ro: high glucose+PKC inhibitor Ro-31-8220 group; B-10: high glucose +10 mmol/L breviscapine; B-20: high glucose+20 mmol/L breviscapine; B-60: high glucose $+60 \mathrm{mmol} / \mathrm{L}$ breviscapine group).

of IVS-to-LVPW $(P<0.05)$. After treatment with breviscapine, the diabetic rats showed improved cardiac function as the parameters of EF, IVS percentage, and LVPW percentage all increased significantly $(P<0.05)$. Also, cardiac hypertrophy was prevented as the IVS-to-LVPW ratio decreased significantly $(P<0.05)$, as shown in Table 3 . The protective effects of breviscapine on cardiac function and hypertrophy were more obvious in the high $\left(25 \mathrm{mg} \cdot \mathrm{kg}^{-1} \cdot \mathrm{d}^{-1}\right)$ dose group than in the low dose $\left(10 \mathrm{mg} \cdot \mathrm{kg}^{-1} \cdot \mathrm{d}^{-1}\right)$ group.

The effects of breviscapine on ultrastructural changes of the diabetic rats' heart tissues by transmission electron microscopy analysis

Electron microscopic analysis of the myocardium revealed a spectrum of abnormalities in the diabetic rats compared with age-matched normal rats. Cardiac muscle cells in diabetic

Table 2. General characteristics of experimental rats.

\begin{tabular}{lccccc}
\hline Groups & BW & BG & LVW/HW (\%) & LVW/BW (\%) & HW/BW (\%) \\
\hline Control & $554.00 \pm 26.05$ & $8.973 \pm 4.403$ & $74.08 \pm 0.259$ & $0.185 \pm 0.012$ & $0.233 \pm 0.017$ \\
DM & $250.00 \pm 31.43^{\mathrm{b}}$ & $20.625 \pm 1.371^{\mathrm{b}}$ & $80.11 \pm 2.302^{\mathrm{b}}$ & $0.235 \pm 0.015^{\mathrm{b}}$ & $0.303 \pm 0.007^{\mathrm{b}}$ \\
DM+LDB & $313.00 \pm 18.19^{\mathrm{e}}$ & $18.511 \pm 1.406^{\mathrm{b}}$ & $76.88 \pm 0.827^{\mathrm{e}}$ & $0.204 \pm 0.000^{\mathrm{e}}$ & $0.275 \pm 0.001^{\mathrm{e}}$ \\
DM+HDB & $357.33 \pm 12.66^{\mathrm{eh}}$ & $19.050 \pm 3.803^{\mathrm{b}}$ & $74.25 \pm 1.211^{\text {eh }}$ & $0.198 \pm 0.002^{\mathrm{e}}$ & $0.267 \pm 0.006^{\mathrm{e}}$ \\
\hline
\end{tabular}

The body weight (BW), blood glucose level (BG), LVW-to-HW, LVW-to-BW, HW-to-BW ratio of all rats in different groups are presented in Table 1 (mean \pm SEM. $n=8-10$ for each group). ${ }^{b} P<0.05$ vs control. ${ }^{\text {e }} P<0.05$ vs DM. ${ }^{\text {h }} P<0.05$ vs $\mathrm{DM}+$ LDB. 

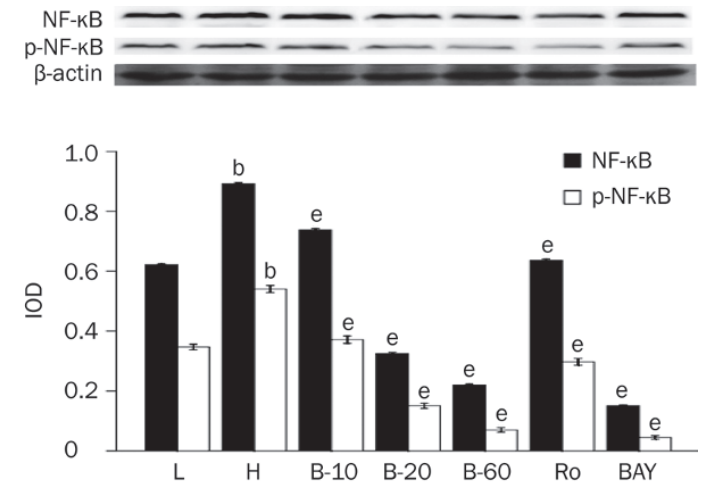

Figure 3. Breviscapine decreased the expression of NF-KB in high glucose cultured cardiomyocytes. Cardiomyocytes cultured in high glucose levels showed higher expression and increased activity of NF-KB compared with control group. After adding PKC inhibitor Ro-31-8220 (50 nmol/L), NF-KB inhibitor BAY11-7082 (5 $\mathrm{mol} / \mathrm{L})$ and breviscapine $(10,20$, and $60 \mathrm{mmol} / \mathrm{L}$ ), the expression and activity of NF-KB decreased as shown in Figure 3. The results were expressed as means \pm SEM. $n=4$ or 5 . ${ }^{\mathrm{b}} P<0.05$ vs control group. ${ }^{\mathrm{e}} P<0.05$ vs high glucose group. (L: control glucose group; $\mathrm{H}$ : high glucose group; Ro: high glucose+PKC inhibitor Ro-31-8220 group; B-10: high glucose+10 mmol/L breviscapine; B-20: high glucose+20 mmol/L breviscapine; B-60: high glucose+60 mmol/L breviscapine group; BAY: high glucose+NF-KB inhibitor BAY11-7082 group).
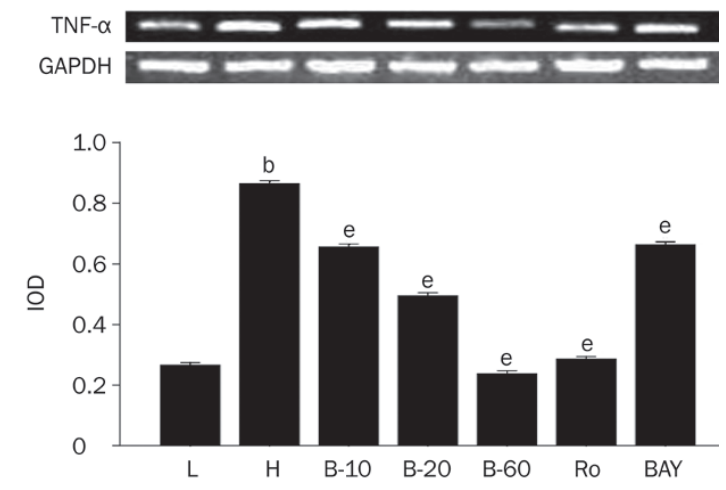

Figure 4. Breviscapine decreased the expression of TNF- $\alpha$ in high glucose cultured cardiomyocytes. Cardiomyocytes cultured in high glucose levels showed higher expression of TNF- $\alpha$ compared with control group. After adding PKC inhibitor Ro-31-8220 (50 nmol/L), NF-KB inhibitor BAY11-7082 (5 $\mu \mathrm{mol} / \mathrm{L})$ and breviscapine (10, 20, and $60 \mathrm{mmol} / \mathrm{L})$, the expression of TNF- $\alpha$ decreased compared with the cardiomyocytes cultured in high glucose levels as shown in Figure 4. The results were expressed as means \pm SEM. $n=4$ or 5 . ${ }^{b} P<0.05$ vs control group. ${ }^{e} P<0.05$ vs high glucose group. (L: control glucose group; $\mathrm{H}$ : high glucose group; Ro: high glucose+PKC inhibitor Ro-31-8220 group; B-10: high glucose+10 $\mathrm{mmol} / \mathrm{L}$ breviscapine; B-20: high glucose+20 mmol/L breviscapine; B-60: high glucose $+60 \mathrm{mmol} / \mathrm{L}$ breviscapine group; BAY: high glucose+NF-KB inhibitor BAY11-7082 group).

hearts showed loss and derangement of myofibrils compared with controls. Swollen, clumped, fragmented and distended mitochondria were evident in diabetic rat hearts, and the cris-
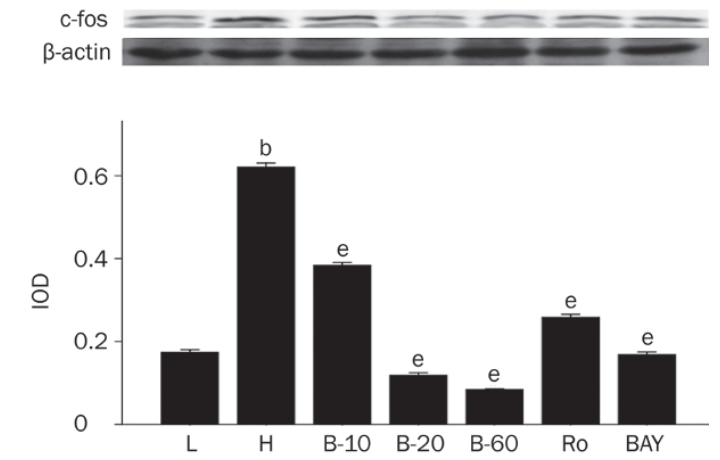

Figure 5. Breviscapine decreased the expression of c-fos in high glucose cultured cardiomyocytes. Cardiomyocytes cultured in high glucose levels showed higher expression of $\mathrm{C}$-fos compared with control group. After adding PKC inhibitor Ro-31-8220 (50 nmol/L), NF-KB inhibitor BAY11$7082(5 \mu \mathrm{mol} / \mathrm{L})$ and breviscapine $(10,20$, and $60 \mathrm{mmol} / \mathrm{L})$, the expression of c-fos decreased as shown in Figure 5. The results were expressed as means \pm SEM. $n=4$ or $5 .{ }^{b} P<0.05$ vs control group. ${ }^{e} P<0.05$ vs high glucose group. (L: control glucose group; $\mathrm{H}$ : high glucose group; Ro: high glucose+PKC inhibitor Ro-31-8220 group; B-10: high glucose+10 $\mathrm{mmol} / \mathrm{L}$ breviscapine; B-20: high glucose $+20 \mathrm{mmol} / \mathrm{L}$ breviscapine; B-60: high glucose $+60 \mathrm{mmol} / \mathrm{L}$ breviscapine group; BAY: high glucose+NF-KB inhibitor BAY11-7082 group).

Table 3. Breviscapine ameliorate cardiac dysfunction in diabetic cardiomyopathy.

\begin{tabular}{lrcrc}
\hline Groups & Control & DM & DM+LDB & DM+HDB \\
\hline EF\% & $0.92 \pm 0.01$ & $0.80 \pm 0.0^{\mathrm{b}}$ & $0.85 \pm 0.02^{\mathrm{e}}$ & $0.89 \pm 0.01^{\text {eh }}$ \\
LVIDd & $0.63 \pm 0.02$ & $0.44 \pm 0.02^{\mathrm{b}}$ & $0.50 \pm 0.01^{\mathrm{e}}$ & $0.54 \pm 0.02^{\text {eh }}$ \\
IVSs/LVPW & $0.64 \pm 0.02$ & $0.75 \pm 0.02^{\mathrm{b}}$ & $0.72 \pm 0.02^{\mathrm{e}}$ & $0.68 \pm 0.01^{\text {eh }}$ \\
IVSd/LVPW & $1.05 \pm 0.07$ & $1.66 \pm 0.10^{\mathrm{b}}$ & $1.55 \pm 0.03^{\mathrm{e}}$ & $1.30 \pm 0.05^{\text {eh }}$ \\
IVS\% & $54.86 \pm 4.47$ & $45.22 \pm 1.24^{\mathrm{b}}$ & $52.47 \pm 2.50^{\mathrm{e}}$ & $57.03 \pm 2.63^{\mathrm{e}}$ \\
LVPW\% & $34.30 \pm 1.69$ & $13.08 \pm 1.38^{\mathrm{b}}$ & $35.33 \pm 1.54^{\mathrm{e}}$ & $35.37 \pm 1.25^{\mathrm{e}}$ \\
\hline
\end{tabular}

The heart EF, LVIDd, IVSs-to-LVPW ratio, IVSd-to-LVPW ratio, IVS\%, LVPW\% of all rats in different groups are presented as the mean \pm SEM in Table 2. $n=8-10$ for each group. ${ }^{\mathrm{b}} P<0.05$ vs control. ${ }^{\mathrm{e}} P<0.05$ vs DM. ${ }^{\mathrm{h}} P<0.05$ vs DM+LDB.

tae in the mitochondria appeared distorted and in some cases were completely lysed. In addition, diabetic rat cardiomyocytes had a dilated and swollen sarcoplasmic reticulum, and the space between the intercalated disks was also widened. Some disks were distorted and ruptured. After treatment with breviscapine, the diabetic rats showed improved cardiac structure with a reversal of the loss and derangement of myofibrils. At the same time, the changes in the mitochondria were reversed, and the dilated and swollen sarcoplasmic reticulum was not as severe as in diabetic rats. The improvement of cardiac structure was more obvious in diabetic rats administered with $25 \mathrm{mg} \cdot \mathrm{kg}^{-1} \cdot \mathrm{d}^{-1}$ breviscapine than in those who received 10 $\mathrm{mg} \cdot \mathrm{kg}^{-1} \cdot \mathrm{d}^{-1}$ breviscapine, so the beneficial effect of breviscapine on the structural changes of diabetic cardiomyopathy may be dose-related, as shown in Figures 6 and 7. 

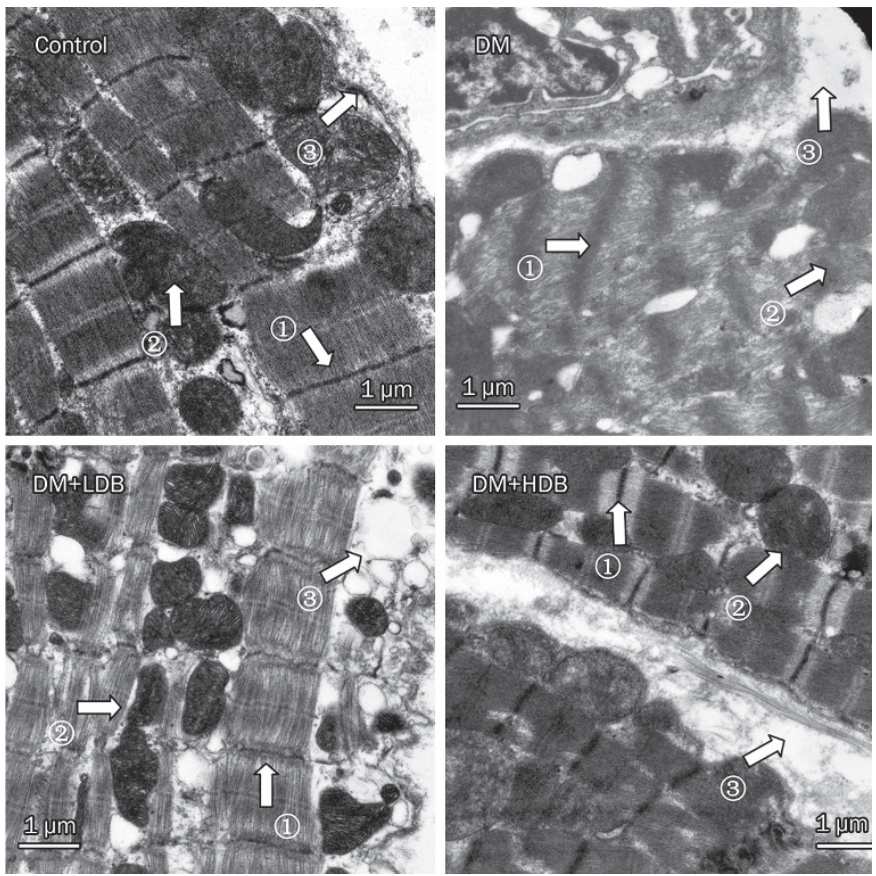

Figure 6. Ultrastructure of myocardium in rats. Control rat $(\times 20000)$; diabetic rat $(D M, \times 20000)$; diabetic rat treated with low dose of breviscapine (DM+LDB, $\times 20000)$; diabetic rat treated with high dose of breviscapine (DM+HDB, $\times 20000)$; (1): the loss and derangement of myofibrils; (2): swollen and distended of mitochondria; (3): dilated and fragmented sarcoplasmic reticulum.
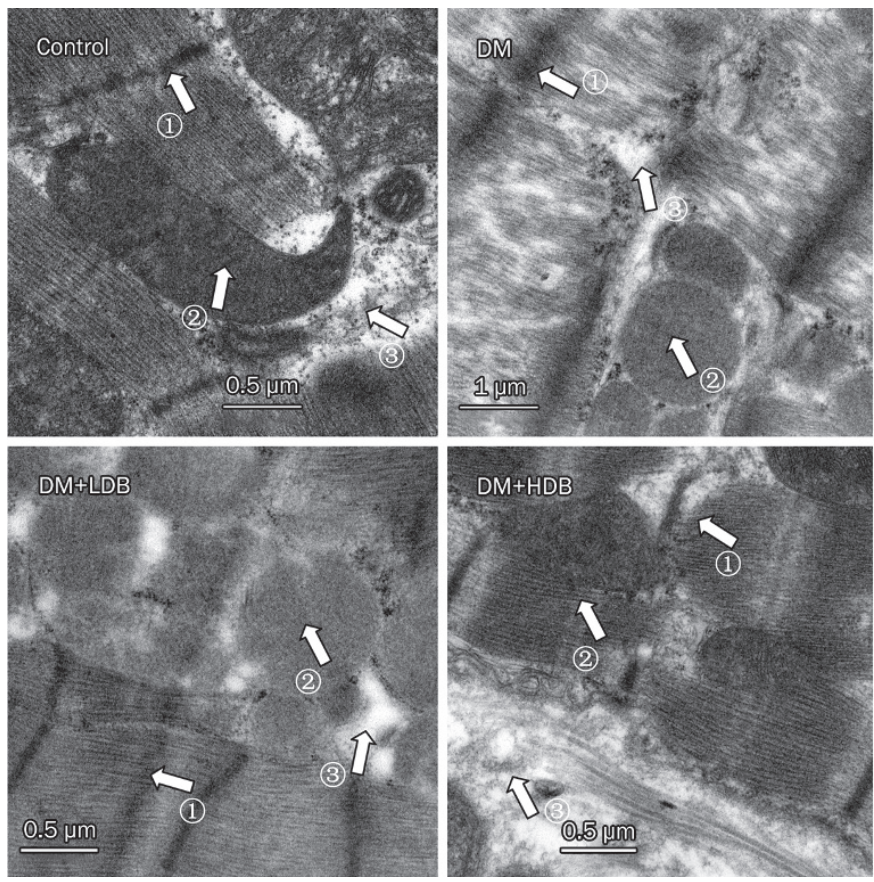

Figure 7. Ultrastructure of myocardium in rats. Control rat $(\times 50000)$; diabetic rat $(\mathrm{DM}, \times 50000)$; diabetic rat treated with low dose of breviscapine $(D M+L D B, \times 50000)$; diabetic rat treated with high dose of breviscapine (DM+HDB, $\times 50000)$. (1): the loss and derangement of myofibrils; (2): swollen and distended of mitochondria; (3): dilated and fragmented sarcoplasmic reticulum.
Breviscapine decreased the expression and activity of PKC- $\alpha$ and PKC- $\beta 2$ in diabetic rat hearts

Protein expression of PKC- $\alpha$ and PKC- $\beta 2$ and their activity, $p-P K C-\alpha$ and $p-P K C-\beta 2$, increased significantly in diabetic rats compared with normal control rats $(P<0.05)$. After treatment with breviscapine, the increased expression of PKC- $\alpha$ and PKC- $\beta 2$ and their activity p-PKC- $\alpha$ and p-PKC- $\beta 2$ in the diabetic rats hearts decreased significantly $(P<0.05)$ as shown in Figures 8 and 9. The reduced expression of PKC- $a, P K C-$ $\beta 2$, p-PKC- $\alpha$, and $p-P K C-\beta 2$ was more obvious in diabetic rats treated with $25 \mathrm{mg} \cdot \mathrm{kg}^{-1} \cdot \mathrm{d}^{-1}$ breviscapine than in those which received $10 \mathrm{mg} \cdot \mathrm{kg}^{-1} \cdot \mathrm{d}^{-1}$ breviscapine, so the protective effect of
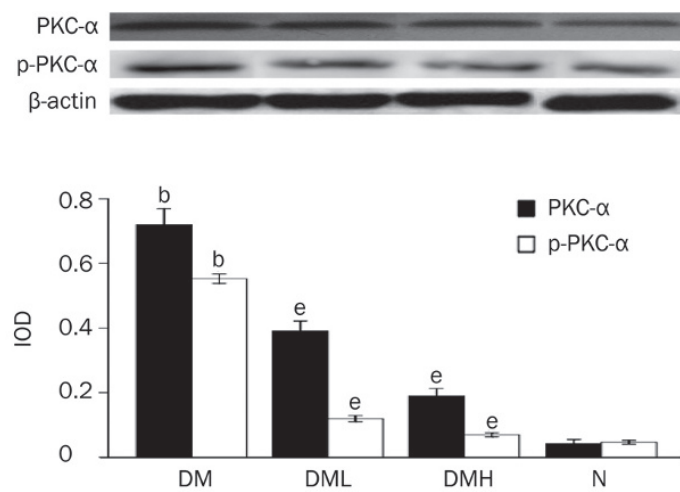

Figure 8. Breviscapine decreased the expression of PKC- $\alpha$ in diabetic rats hearts. Diabetic rats (DM) showed higher expression of PKC- $\alpha$ in heart tissues compared with normal control ones (Control) analyzed by Western blot. Treatment with breviscapine reduced the expression of PKC- $\alpha$ in diabetic cardiomyopathy, the reduced expression of PKC- $\alpha$ was more obvious in diabetic rats treated with breviscapine $25 \mathrm{mg} \cdot \mathrm{kg}^{-1} \cdot \mathrm{d}^{-1}(\mathrm{DM}+\mathrm{HDB})$ than those received $10 \mathrm{mg}^{\mathrm{kg}} \mathrm{k}^{-1} \cdot \mathrm{d}^{-1}$ breviscapine (DM+LDB), $\beta$-actin was an endogenous control. Each bar represents the mean \pm SEM. $n=8-10$ rats for each group. ${ }^{b} P<0.05$ vs control group. ${ }^{e} P<0.05$ vs high glucose group.

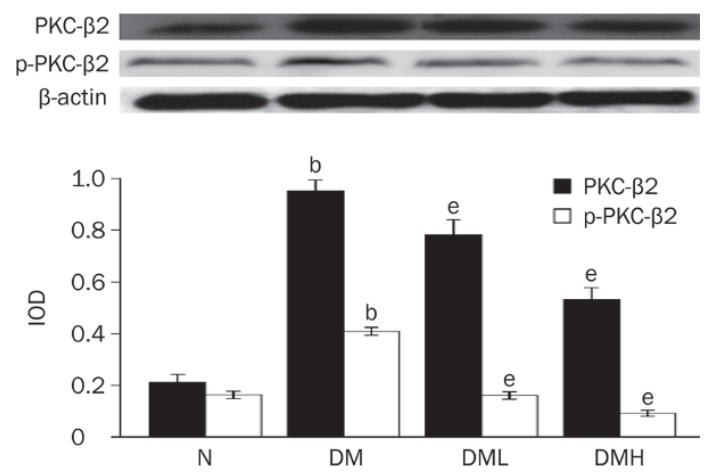

Figure 9. Breviscapine decreased the expression of PKC- $\beta 2$ in diabetic rats hearts. Diabetic rats (DM) showed higher expression of PKC- $\beta 2$ in heart tissues compared with normal control rats (Control). Treatment with breviscapine could reduced the expression of PKC- $\beta 2$ in diabetic cardiomyopathy, the reduced expression of PKC- $\beta 2$ was more obvious in diabetic rats treated with $25 \mathrm{mg} \cdot \mathrm{kg}^{-1} \cdot \mathrm{d}^{-1}(\mathrm{DM}+\mathrm{HDB})$ breviscapine than those received $10 \mathrm{mg} \cdot \mathrm{kg}^{-1} \cdot \mathrm{d}^{-1}$ breviscapine $(\mathrm{DM}+\mathrm{LDB}), \beta$-actin was an endogenous control. Each bar represents the mean \pm SEM. $n=8-10$ rats for each group. ${ }^{b} P<0.05$ vs control. ${ }^{e} P<0.05$ vs DM. 
breviscapine on diabetic cardiomyopathy may be dose-related.

Breviscapine decreased the expression of NF-KB, TNF- $\alpha$, and c-fos in diabetic rat hearts

Protein expression of NF- $\mathrm{kB}$ and c-fos as well as the mRNA level of TNF-a significantly increased in diabetic rats compared with normal control rats $(P<0.05)$. After treatment with breviscapine, the increased protein expression of NF-kB, TNF- $\alpha$ and $c-$ fos in diabetic rats heart decreased $(P<0.05)$ as shown in Figures 10, 11, and 12 . The regulatory effect of breviscapine on the expression of NF-kB, TNF- $\alpha$, and c-fos was more obvious in diabetic rats treated with $25 \mathrm{mg} \cdot \mathrm{kg}^{-1} \cdot \mathrm{d}^{-1}$ breviscapine than in those who received $10 \mathrm{mg} \cdot \mathrm{kg}^{-1} \cdot \mathrm{d}^{-1}$ breviscapine.

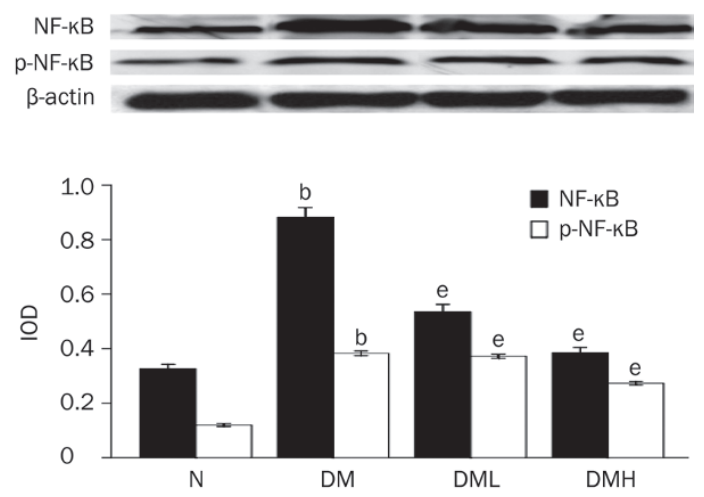

Figure 10. Breviscapine decreased the expression of NF-KB in diabetic rats hearts. Diabetic rats (DM) showed higher expression of NF-KB in heart tissues compared with normal control rats (Control). Treatment with breviscapine reduced the expression of NF-KB in diabetic cardiomyopathy, the reduced expression of NF-KB was more obvious in diabetic rats treated with breviscapine $25 \mathrm{mg} \cdot \mathrm{kg}^{-1} \cdot \mathrm{d}^{-1}(\mathrm{DM}+\mathrm{HDB})$ than those received $10 \mathrm{mg} \cdot \mathrm{kg}^{-1} \cdot \mathrm{d}^{-1}$ breviscapine (DM+LDB), $\beta$-actin was an endogenous control. Each bar represents the mean \pm SEM. $n=8-10$ rats for each group. ${ }^{\mathrm{b}} P<0.05$ vs control. ${ }^{\mathrm{e}} \mathrm{P}<0.05$ vs DM.
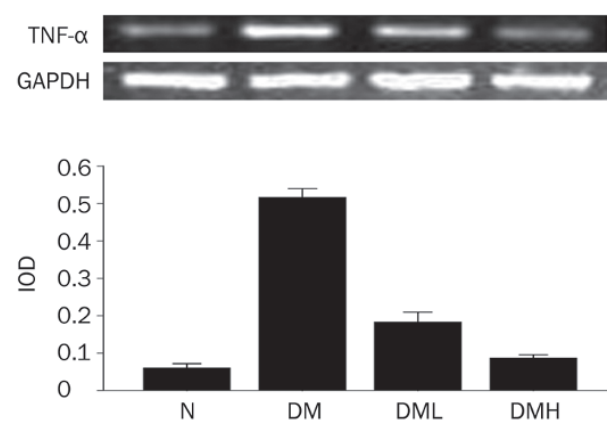

Figure 11. Breviscapine decreased the expression of TNF- $\alpha$ in diabetic rats hearts. Diabetic rats (DM) showed higher expression of TNF- $\alpha$ in heart tissues compared with normal control rats (Control) analyzed by RT-PCR. Treatment with breviscapine reduced the expression of TNF- $\alpha$ in diabetic cardiomyopathy, the reduced expression of TNF- $\alpha$ was more obvious in diabetic rats treated with breviscapine $25 \mathrm{mg}^{\mathrm{kg}} \mathrm{kg}^{-1} \cdot \mathrm{d}^{-1}(\mathrm{DM}+\mathrm{HDB})$ than those received $10 \mathrm{mg} \cdot \mathrm{kg}^{-1} \cdot \mathrm{d}^{-1}$ breviscapine (DM+LDB), GAPDH was an endogenous control. Each bar represents the mean \pm SEM. $n=8-10$ rats for each group. ${ }^{b} P<0.05$ vs control. ${ }^{e} P<0.05$ vs $D$ M.
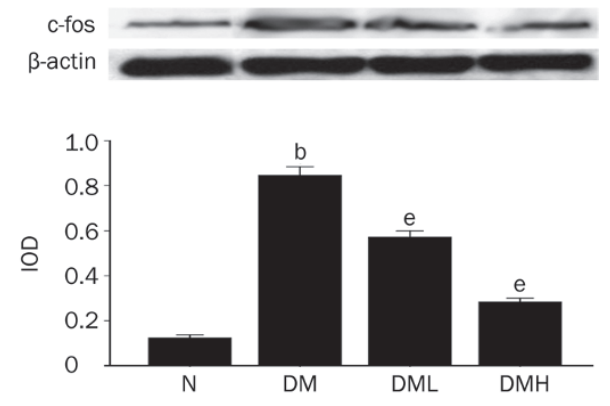

Figure 12. Breviscapine decreased the expression of c-fos in diabetic rats hearts. Diabetic rats (DM) showed higher expression of c-fos in heart tissues compared with normal control rats (Control). Treatment with breviscapine reduced the expression of c-fos in diabetic cardiomyopathy, the reduced expression of $\mathrm{c}$-fos was more obvious in diabetic rats treated with breviscapine $25 \mathrm{mg} \cdot \mathrm{kg}^{-1} \cdot \mathrm{d}^{-1}(\mathrm{DM}+\mathrm{HDB})$ than those received 10 $\mathrm{mg} \cdot \mathrm{kg}^{-1} \cdot \mathrm{d}^{-1}$ breviscapine (DM+LDB), $\beta$-actin was an endogenous control. Each bar represents the mean \pm SEM. $n=8-10$ rats for each group. ${ }^{\mathrm{b}} P<0.05$ vs control. ${ }^{\mathrm{e}} \mathrm{P}<0.05$ vs $\mathrm{DM}$.

\section{Discussion}

Diabetic cardiomyopathy is one of the most prevalent cardiovascular complications of diabetes mellitus, occurring independently of coronary artery disease and hypertension ${ }^{[2]}$. The associated typical pathological changes include hypertrophy of cardiomyocytes, microangiopathy of the heart and fibrosis of the interstitial substance ${ }^{[23]}$. Cardiomyopathy in diabetic patients is characterized by early diastolic dysfunction, followed by late systolic dysfunction ${ }^{[24-26]}$. However, the mechanism underlying the development of structural and functional impairment in cardiomyopathy remains unknown; in particular, the intracellular signal transduction pathway that leads to the pathological change of cardiomyocyte hypertrophy is still unclear.

Previous studies have indicate that high glucose levels could induce structural and functional changes in cardiac myocytes. In this study, we discovered that cardiomyocytes cultured in high levels of glucose showed increased pulsatile frequency and obvious hypertrophy compared with cells cultured in normal glucose levels, which correlates with previous studies. High glucose could increase the pulsatile frequency of cardiomyocytes by regulating the opening of voltage-dependent channels that exist in the cytoplasmic membrane due to activation of tyrosine kinase ${ }^{[27]}$. Accelerated pulsatile frequency causes increased energy expenditure, leading to energy insufficiency and a series of negative manifestations, which aggravate the impairment of cardiomyocytes induced by high glucose levels.

We found that diabetic rats had a lower body weight, higher blood glucose level, relative cardiac hypertrophy and impaired cardiac function compared with those of the age-matched control rats. Breviscapine treatment did not influence the average blood glucose levels, but the body weight increased, and the cardiac hypertrophy and the impaired cardiac dysfunction were also reversed in diabetic rats. The improvement of car- 
diac hypertrophy and cardiac dysfunction was more obvious in diabetic rats administrated with $25 \mathrm{mg} \cdot \mathrm{kg}^{-1} \cdot \mathrm{d}^{-1}$ breviscapine than in those that received $10 \mathrm{mg} \cdot \mathrm{kg}^{-1} \cdot \mathrm{d}^{-1}$ breviscapine. Therefore, breviscapine has a protective effect on both the structural changes and cardiac dysfunction found in diabetic cardiomyopathy.

To investigate whether the protective effect of breviscapine is related to PKC, we examined the expression of PKC in cardiomyocytes. We found that both the cardiomyocytes cultured in high glucose levels and the myocardium of diabetic rats showed increased expression and activity of PKC- $a$ and PKC$\beta 2$, as reflected by the higher protein expression of PKC- $\alpha$, PKC- $\beta 2$, p-PKC- $\alpha$, and p-PKC- $\beta 2$ when examined by Western blot. This is in agreement with similar studies on diabetic and heart failure animal models ${ }^{[28,29]}$. After treatment with breviscapine, both the cardiomyocytes cultured in high levels of glucose and the diabetic rat hearts showed decreased expression of PKC- $\alpha$ and PKC- $\beta 2$, and the activity of PKC- $\alpha$ and PKC- $\beta 2$ also decreased significantly, which indicated that increased levels of PKC- $\alpha$ and PKC- $\beta 2$ are involved in the pathogenesis of diabetic cardiomyopathy, and breviscapine has a protective effect on the diabetic cardiomyopathy.

Thus, pharmacological inhibition of PKC activity could reverse the hypertrophic changes in the myocardium in diabetic cardiomyopathy. There have been some studies on the therapeutic action of PKC inhibitors on heart failure and ischemic injury. Studies that were done on ischemic and heart failure animal models have also shown that NF-KB activation as well as TNF-a were closely related to cardiac hypertrophy, and over-expression of PKC could induce the expression of proto-oncogenes such as c-fos and c-jun, leading to increased activator protein one (AP-1) expression. AP-1 potentially stimulates the transcription of type IV collagen, fibronectin, TGF- $\beta$ and so on, leading to decreased contractility and permeability of cardiomyocytes. This causes changes in the extracellular matrix and induces hypertrophy of cardiomyocytes, microangiopathy of the heart and fibrosis of the interstitial substance, which ultimately leads to heart failure.

In this study, we have found that the expression of NF-kB, TNF- $\alpha$ and c-fos of the cardiomyocytes cultured in the high glucose levels as well as diabetic rat hearts increased compared with those of control groups. To investigate the mechanism of action of PKC on the structural and functional changes of diabetic cardiomyopathy, we used a PKCa/ $\beta 2$ inhibitor (Ro-31-8220) and an NF-KB inhibitor (BAY11-7082) to study the signal transduction pathway of PKC and its downstream effects. We discovered that the increased beating frequency and hypertrophy of cardiomyocytes induced by high glucose level were obviously reversed after using the selective $\mathrm{PKCa} /$ $\beta 2$ inhibitor Ro-31-8220, with depressed expression and activity of PKC- $\alpha$ and PKC- $\beta 2$ and a remarkably decreased expression pattern of NF-kB, TNF- $\alpha$, and c-fos. Similarly, after using the NF-кB inhibitor, BAY11-7082, the increased beating frequency and cardiac hypertrophy were also reversed, and the expression of NF-kB, TNF- $\mathrm{a}$, and c-fos were also remarkably reduced. Due to this phenomenon, we hypothesize that hyperglycemia could result in a higher content of intracellular DAG in the cardiomyocytes cultured in high levels of glucose, leading to increased expression and activity of PKC-a and PKC- $\beta 2$, which induce over-expression of NF-KB via the $\mathrm{PKC}-\mathrm{IKK}-\mathrm{NF}-\mathrm{KB}$ signal transduction pathway. NF- $\mathrm{KB}$ is a transcription factor that can directly regulate the expression of immediate-early genes and other genes that are involved in the stress response following a variety of physiological or pathological stimuli ${ }^{[30,31]}$. Activation of NF- $\mathrm{KB}$ is necessary and sufficient for the hypertrophic response in heart failure, as modeled in cultured cardiomyocytes. Recent studies have shown that oxidative stress generated by hyperglycemia is one of the major mediators of diabetic cardiomyopathy, and that the activation of NF-kB is one possible mechanism for the oxidative stress-induced vascular complications in diabetes. Therefore, NF-kB may function as a causal event in the cardiac hypertrophic response of diabetic cardiomyopathy. It is clear that after entering the cellular nucleus, NF- $\mathrm{KB}$ could increase the transcription of TNF- $\mathrm{a}$ and NF-KB itself is dominantly regulated by the cytokine TNF- $\mathrm{a}^{[32,33]}$. TNF- $\mathrm{a}$ is one of the relevant mediators of cardiomyopathic disease and is considered to be a parameter of hypertrophy that could be induced by angiotension II, endothelin-1, phenylephrine, myotrophin and so on. Increased expression of TNF-a could obviously have been inhibited through over-expression of the degradationresistant mutant of IKBa ${ }^{[34-37]}$, which supports the hypothesis that NF-KB inhibition could attenuate or block the hypertrophic response of cultured cardiomyocytes. There have been studies that show that the increased expression of TNF-a could further lead to the expression of proto-oncogenes such as c-fos, which cause increased cell size and protein content of cardiomyocytes. This results in an accelerated rate of general protein synthesis, as well as an increase in ventricular mass, including the accumulation of collagen fibers, deposition of collagen protein and fibrosis of the interstitial substance in the interstitial tissue of the heart. Increased expression of c-fos was viewed as an adaptive response for maintaining cardiac output after stimulation with TNF-a or angiotensin II, as in isolated adult cardiac myocytes or heart failure, ischemic injury and stress-induced hypertrophy models. Those pathological changes ultimately result in remodeling of the cardiac muscle, leading to the development of diabetic cardiomyopathy. PKC may lead to diabetic cardiomyopathy via the PKC/ NF-kB/TNF-a/c-fos signal transduction pathway.

Breviscapine is isolated from the Asteraceae plant $E$ breviscapus and can be prepared as a Chinese patent medicine, where the essential active ingredients are flavones ${ }^{[38,39]}$. It possesses an anti-platelet and anti-thrombus action and can lower plasma fibrin content and promote fibrinolytic activity. Studies have found that breviscapine could inhibit the activity of PKC, promote apoptosis of cardiomyocytes via regulation of the expression of the apoptosis-inhibiting gene bcl- $2^{[40,41]}$ and have a protective effect against ischemia/reperfusion injury. It has been used in cardiovascular disease with satisfactory tolerance and safety. It has also been proved that breviscapine can significantly inhibit increased PKC- $\beta$ expression and 
activity seen in diabetic nephropathy in the same manner as LY-333531 $1^{[42]}$. Our research has found that breviscapine inhibits PKC expression both in cardiomyocytes cultured in high concentrations of glucose and in diabetic hearts, and can reverse the hypertrophic changes and cardiac dysfunction found in diabetic cardiomyopathy. We also found that cardiomyocytes cultured in high concentrations of glucose and diabetic rats treated with breviscapine showed decreased expression of NF-kB, TNF- $\alpha$, and c-fos, which was consistent with the change in PKC expression. In summary, breviscapine may have a protective effect against diabetic cardiomyopathy via the PKC-induced NF-kB/TNF-a/c-fos signal transduction pathway.

In conclusion, PKC is involved in the pathogenesis of diabetic cardiomyopathy, and the PKC/NF-kB/TNF-a/c-fos signal transduction pathway plays an important role in regulating cardiac hypertrophy. Treatment with breviscapine can significantly reverse the cardiac structure disorganization and ameliorate cardiac dysfunction in diabetic cardiomyopathy.

\section{Acknowledgements}

We thank the Department of Cardiovascular Diseases, Sir Run Run Shaw Hospital, College of Medicine, Zhejiang University for the use of test instruments and equipment.

\section{Author contribution}

Bin-quan ZHOU designed research; Min WANG performed research; Jun-hui ZHU contributed new analytical tools and reagents; Guo-sheng FU analyzed data; Min WANG and Wenbin ZHANG wrote the paper.

\section{References}

1 Wild S, Roglic G, Green A, Sicree R, King H. Global prevalence of diabetes: estimates for the year 2000 and projections for 2030. Diabetes Care 2004; 27: 1047-53.

2 Boudina S, Abel ED. Diabetic cardiomyopathy revisited. Circulation 2007; 115: 3213-23.

3 Brownlee M. The pathobiology of diabetic complications: a unifying mechanism. Diabetes 2005; 54: 1615-25.

4 Beckman JA, Goldfine AB, Gordon MB, Garret LA, Creager MA. Inhibition of protein kinase $C$ beta prevents impaired endotheliumdependent vasodilation caused by hyperglycaemia in humans. Circ Res 2002; 90: 107-11.

5 Quagliaro L, Piconi L, Assaloni R, Martinelli L, Motz E, Ceriello A. Intermittent high glucose enhances apoptosis related to oxidative stress in human umbilical vein endothelial cells: the role of protein kinase $\mathrm{C}$ and NAD(P)H-oxidase activation. Diabetes 2003; 52: 2795804.

6 Naruse K, King GL. Protein kinase $\mathrm{C}$ and myocardial biology and function. Circ Res 2000; 86: 1104-6.

7 Idris I, Gray S, Donnelly R. Protein kinase C activation: isozymespecific effects on metabolism and cardiovascular complications in diabetes. Diabetologia 2001; 4: 659-73.

8 Farese RV, Sajan MP, Standaert ML. Atypical protein kinase C in insulin action and insulin resistance. Biochem Soc Trans 2005; 33 (Pt 2): $350-3$

9 Das EN, King GL. The role of protein kinase C activation and the vascular complications of diabetes. Pharmacol Res 2007; 55: 498-
510.

10 Hall G, Hasday JD, Rogers TB. Regulating the regulator: NF-kappa B signaling in heart. J Mol Cell Cardiol 2006; 41: 580-91.

11 Purcell NH, Tang GL, Yu CF, Mercurio F, DiDonato JA, Lin AN. Activation of NF-KB is required for hypertrophic growth of primary rat neonatal ventricular cardiomyocytes. Cell Biol 2001; 98: 6668-73.

12 Hemandez GS, Rojas CE. Role of the transcription factor NF-kappaB in the cardiac cell. Arch Cardiol Mex 2005; 75: 363-70.

13 Freund C, Schmidt-Ullirrich R, Baurand A, Dunger S, Schneider W. Requirement of nuclear factor-kappaB in angiotensin II- and isoproterenol-induced cardiac hypertrophy in vivo. Circulation 2005; 111: 2319-25.

14 Wang BW, Hung HF, Chang H, Kuan PL, Kou-Gi Shyu. Mechanical stretch enhances the expression of resistin gene in cultured cardiomyocytes via tumor necrosis factor- $\alpha$. Am J Physiol Heart Circ Physiol 2007; 293: H2305-H2312.

15 Coronella-Wood J, Terrand J, Sun H, Chen QM. c-fos phosphorylation induced by $\mathrm{H}_{2} \mathrm{O}_{2}$ prevents proteasomal degradation of $\mathrm{c}$-fos in cardiomyocytes. J Biol Chem 2004; 279: 33567-74.

16 Zhu XX, Niu XL, Chen DZ, Zhou XD, Pei JM, Zhu MZ, et al. Inhibitory effects of rosiglitazone against endothelin-1-induced proliferation of rat cardiac myocytes: the role of PKC-c-fos pathway. Nan Fang Yi Ke Da Xue Xue Bao 2008; 28: 1056-60. Chinese.

17 Zhou H, Chen S, Wang L, He Q, Fan X. Regulation of the expression of pulmonary arterial collagen by protein kinase $\mathrm{C}$ and breviscapine in chronic hypoxic rats. Zhonghua Jie He He Hu Xi Za Zhi 2002; 25: 347-51. Chinese.

18 Zhang SJ, Song Y, Zhai WL, Shi JH, Feng LS, Zhao YF, et al. Breviscapine alleviates hepatic injury and inhibits PKC-mRNA and its protein expression in brain-dead BA-Ma mini pigs. Hepatobiliary Pancreat Dis Int 2007; 6: 604-9.

19 Zhou W, Wang XL, Lamping KG, Lee HC. Inhibition of protein kinase $\mathrm{C}$ beta protects against diabetes induced impairment in arachidonic acid dilation of small coronary arteries. J Pharmacol Exp Ther 2006; 319: 199-207.

20 Clark WA, Decker ML, Behnke-Barclay M, Janes DM, Decker RS. Cell contact as an independent factor modulating cardiac myocyte hypertrophy and survival in long-term primary culture. J Mol Cell Cardiol 1998; 30: 139-55.

21 Yonemochi H, Yasunaga S, Teshima Y, Iwao T, Akiyoshi K, Nakagawa M, et al. Mechanism of beta-adrenergic receptor upregulation induced by ACE inhibition in cultured neonatal rat cardiac myocytes: roles of bradykinin and protein kinase C. Circulation 1998; 97: 2268-73.

22 Jun Ren, Dominguez $\sqcup$, Sowers JR, Davidoff AJ. Metformin but not glyburide prevents high glucose-induced abnormalities in relaxation and intracellular $\mathrm{Ca}^{2+}$ transients in adult rat ventricular myocytes. Diabetes 1999; 48: 2059-65.

23 Devereux RB, Roman MJ, Paranicas M, O'Grady MJ, Lee ET, Welty TK, et al. Impact of diabetes on cardiac structure and function: the strong heart study. Circulation 2000; 101: 2271-6.

24 Schannwell CM, Schneppenheim M, Perings S, Plehn G, Strauer BE. Left ventricular diastolic dysfunction as an early manifestation of diabetic cardiomyopathy. Cardiology 2002; 98: 33-9.

25 Poirier P, Bogaty P, Garneau C, Marois L, Dumesnil JG. Diastolic dysfunction in normotensive men with well-controlled type 2 diabetes: importance of maneuvers in echocardiographic screening for preclinical diabetic cardiomyopathy. Diabetes Care 2001; 24: 5-10.

26 Vasanji Z, Cantor EJ, Juric D, Moyen M, Netticadan T. Alterations in cardiac contractile performance and sarcoplasmic reticulum function in sucrose-fed rats is associated with insulin resistance. Am J Physiol Cell Physiol 2006; 291: C772-C780. 
27 Zhou QF, Wang HX, Wang GJ, Yang YH. Accelerating effect of high glucose on NE-induced cardiac hypertrophy of the cultured myocardial cells. Chin Pharmacol Bull 2003; 19: 1054-7.

28 Braz JC, Gregory K, Pathak A, Zhao W, Sahin B, Klevitsky R, et al. $\mathrm{PKC}$-alpha regulate cardiac contractility and propensity toward heart failure. Nat Med 2004; 10: 248-54.

29 Hahn HS, Marreez Y, Odley A, Sterbling A, Yussman MG, Hilty KC, et al. Protein kinase $\mathrm{C}-\alpha$ negatively regulates systolic and diastolic function in pathological hypertrophy. Circ Res 2003; 93: 1111-9.

30 Alter P, Rupp H, Maisch B. Activated nuclear transcription factor kappaB in patients with myocarditis and dilated cardiomyopathyrelation to inflammation and cardiac function. Biochem Biophys Res Commun 2006; 339: 180-7.

31 Abe J. Role of PKCs and NF-kappaB activation in myocardial inflammation: enemy or ally? J Mol Cell Cardiol 2007; 43: 404-8.

32 Higuchi Y, Otsu K, Nishida K, Hirotani S, Nakayama H, Yamaguchi O, et al. Involvement of reactive oxygen species-mediated NF-kappa B activation in TNF-alpha-induced cardiomyocyte hypertrophy. J Mol Cell Cardiol 2002; 34: 233-40.

33 Higuchi Y, Chan TO, Brown MA, Zhang J, DeGeorge BR Jr, Funakoshi H, et al. Cardioprotection afforded by NF-kappaB ablation is associated with activation of Akt in mice overexpressing TNF-alpha. Am J Physiol Heart Circ Physiol 2006; 290: H590-598.

34 Sármán B, Skoumal R, Leskinen H, Rysä J, Ilves M, Soini Y, et al. Nuclear factor-kappaB signaling contributes to severe, but not moderate, angiotensin II-induced left ventricular remodeling. J Hypertens 2007; 25: 1927-39.
35 Mathes E, O'Dea EL, Hoffmann A, Ghosh G. NF-kappaB dictates the degradation pathway of IkappaB-alpha. EMBO J 2008; 27: 1357-67.

36 Moss NC, Stansfield WE, Willis MS, Tang RH, Selzeman CH. IKKbeta inhibition attenuates myocardial injury and dysfunction following acute ischemia-reperfusion injury. Am J Physiol Heart Circ Physiol 2007; 293: H2248-H2253.

37 Kawamura N, Kubota T, Kawano S, Monden Y, Feldman AM, Tsutsui H, et al. Blockade of NF-kappaB improves cardiac function and survival without affecting inflammation in TNF-alpha-induced cardiomyopathy. Cardiovasc Res 2005; 66: 520-9.

38 Lin LL, Liu AJ, Liu JG, Yu XH, Qin LP, Su DF. Protective effects of scutellarin and breviscapine on brain and heart ischemia in rats. J Cardiovasc Pharmacol 2007; 50: 327-32.

39 Li XL, Li YQ, Yan WM, Li HY, Xu H, Zheng XX, et al. A study of the cardioprotective effect of breviscapine during hypoxia of cardiomyocytes. Planta Med 2004; 70: 1039-44.

40 Li FQ, Chen YZ. Effects of scutellarein on cardiomyocyte apoptosis and ventricular remodeling in spontaneously hypertensive rats. J Chongqing Med Univ 2002; 27: 400-2.

41 Liu XD, Chen YZ. The effects of breviscapine on cardiac myocyte apoptosis and expression of $\mathrm{Bcl}-2$ during myocardial ischemia/ reperfusion course in rats. J Guiyang Med Coll 2004; 29: 102-4.

42 Wu YG, Wu GZ, Qi XM, Lin H, Qian H, Shen JJ, et al. Protein kinase C $\beta$ inhibitor LY333531 attenuates intercellular adhesion molecule-1 and monocyte chemotactic protein-1 expression in the kidney in diabetic rats. J Pharmacol Sci 2006; 101: 335-43. 